\title{
Genistein and menaquinone-4 treatment-induced alterations in the expression of $m R N A s$ and their products are beneficial to osteoblastic MC3T3-E1 cell functions
}

\author{
MIDORI KATSUYAMA ${ }^{1}$, MASASHI DEMURA ${ }^{1}$, HIRONOBU KATSUYAMA ${ }^{2}$, \\ HIDEJI TANII $^{1}$ and KIYOFUMI SAIJOH ${ }^{1}$
}

${ }^{1}$ Department of Hygiene, Kanazawa University School of Medicine, Kanazawa, Ishikawa 920-8640;
${ }^{2}$ Department of Public Health, Kawasaki Medical University, Kurashiki, Okayama 701-0192, Japan

Received September 13, 2016; Accepted March 21, 2017

DOI: $10.3892 / \mathrm{mmr} .2017 .6632$

\begin{abstract}
The aim of the present study was to determine the molecular basis of the beneficial effects of genistein and/or menaquinone-4 (MK-4) on bone quality. Initially, $1 \mu \mathrm{M}$ genistein was applied to MC3T3-E1 cells for $24 \mathrm{~h}$ and the upregulated mRNAs that were detected by microarray were selected for further examination by reverse transcription-quantitative-polymerase chain reaction. Among them, alterations were observed in the level of GATA-binding protein 6 (GATA6), Notch gene homolog 2 (NOTCH2), Wnt family member 5A (WNT5A), bone $\gamma$-carboxyglutamate protein (BGLAP), chondroadherin (CHAD), dipeptidyl peptidase 4 (DPP4), ectonucleotide pyrophosphatase/phosphodiesterase 2 (ENPP2), alkaline phosphatase (ALP) 3 and ATPase phospholipid-transporting $11 \mathrm{~A}$ (ATP11A) in response to treatment with $0.1 \mu \mathrm{M} 17-\beta$-estradiol, $1 \mu \mathrm{M}$ genistein, and/or $1 \mu \mathrm{M}$ MK-4. GATA6, NOTCH2 and WNT5A are considered to be associated with osteoclast, but not osteoblast, function; however, increases in osteoblastic mRNAs, including BGLAP and CHAD, were observed in each of the treatment groups at $48 \mathrm{~h}$. Immunocytochemical analysis confirmed an increase in CHAD and DPP4 proteins following the administration of genistein + MK-4. Furthermore, genistein + MK-4 led to alterations in cell morphology to spindle or oval shapes, and increased the intensity of ALP staining. Although the level of ALP mRNA was not consistently altered in response to the treatments, a marked increase in ALP activity was observed following $96 \mathrm{~h}$ treatment with genistein + MK-4. Therefore, the simultaneous intake of genistein and MK-4 appears to be beneficial for the maintenance of bone quality.
\end{abstract}

Correspondence to: Dr Kiyofumi Saijoh, Department of Hygiene, Kanazawa University School of Medicine, 13-1 Takaramachi, Kanazawa, Ishikawa 920-8640, Japan

E-mail: saijohk@med.kanazawa-u.ac.jp

Key words: genistein, menaquinone-4, osteoblastic MC3T3-E1 cells, chondroadherin, dipeptidyl peptidase 4 , alkaline phosphatase

\section{Introduction}

Bone is a basic component of the musculoskeletal system and is constantly remodeled by the function of osteoblasts and osteoclasts (1-3). This bone remodeling is maintained in men throughout life, whereas following menopause, women exhibit accelerated bone loss due to a decrease in estrogen levels, leading to osteoporosis (4). Osteoporosis is a serious social and health problem in a progressively aging society, and the associated increases in medical expenditure have become a serious problem in developed and developing countries (5). Various epidemiological studies have demonstrated that the intake of various vitamins and phytoestrogens can act to support the enrichment of bone mineral density (BMD) (6). Therefore, utilization of food-based nutrients is considered to be the most economical and simple way to prevent bone loss. For example, genistein, which has a similar structure to estrogen, has been demonstrated to aid in maintaining BMD (6-9). Furthermore, the simultaneous intake of genistein and menaquinone-7 (MK-7), a major form of vitamin $\mathrm{K}_{2}$, is considered to be more effective for the maintenance of BMD (10-12). However, MK-7 is only present in fermented foods. For example, the traditional Japanese food, Nattō, a type of fermented soybean, is considered to be beneficial; however, due to its peculiar smell, its intake is not always common, even in Japan (10), and non-Japanese experience difficulty with its intake.

In addition to the extremely high concentration of MK-7 in Nattō (13), another major form of vitamin $\mathrm{K}_{2}$, menaquinone-4 (MK-4) is found in meat, eggs and dairy foods; however, its concentration is often low $(14,15)$. In addition, the bioavailability of MK-4 is unclear (16).

In the present study, the effects of genistein and/or MK-4 at dietary obtainable concentrations on the level of mRNAs and their protein products in MC3T3-E1 cells derived from neonatal mouse calvaria were evaluated.

\section{Materials and methods}

Reagents. Fetal bovine serum (FBS), and phenol red-free Eagle's minimal essential medium, $\alpha$-modification ( $\alpha$-MEM), were obtained from Thermo Fisher Scientific, Inc. (Osaka, 
Japan). Genistein, 17- $\beta$-estradiol and MK-4 were purchased from Sigma-Aldrich; Merck KGaA (Darmstadt, Germany), and dissolved in ethanol (Nacalai Tesque, Inc., Kyoto, Japan).

MC3T3-E1 cell culture, treatment and RNA preparation. Osteoblastic MC3T3-E1 cells derived from the calvaria of a newborn C57BL/6 mouse were obtained from the Riken Cell Bank (Tokyo, Japan) and used at passages 3-5. The cells were maintained in $\alpha$-MEM containing $10 \%$ (v/v) FBS. All cells were plated at a density of $1 \times 10^{5}$ cells in $10-\mathrm{cm}$ culture dishes, and incubated at $37^{\circ} \mathrm{C}$ in a humidified atmosphere containing $5 \% \mathrm{CO}_{2}$. When subconfluent, the cells were subcultured into $35-\mathrm{mm}$ dishes at a density of $1 \times 10^{5}$ cells and then cultured with the media containing $0.1 \%$ ethanol (control), $0.1 \mu \mathrm{M}$ 17- $\beta$-estradiol, $1 \mu \mathrm{M}$ genistein, $1 \mu \mathrm{M}$ MK-4, $17-\beta$-estradiol + genistein $(0.1 \mu \mathrm{M}+1 \mu \mathrm{M}), 17-\beta$-estradiol $+\mathrm{MK}-4(0.1 \mu \mathrm{M}+$ $1 \mu \mathrm{M})$ or genistein $+\mathrm{MK}-4(1 \mu \mathrm{M}+1 \mu \mathrm{M})$ for 24,48 or $96 \mathrm{~h}$. The total RNA was extracted from 24 and $48 \mathrm{~h}$ cell cultures using ISOGEN reagent (Nippon Gene Co., Ltd., Tokyo, Japan). All total RNA samples were quality checked by RNA Pico Chips using an Agilent 2100 Bioanalyzer (Agilent Technologies, Inc., Santa Clara, CA, USA), and treated with RNase-free DNase I recombinant (Roche Diagnostics GmbH, Mannheim, Germany) to isolate DNA-free RNA.

Identification of mRNA species upregulated by genistein. From each $24 \mathrm{~h}$ culture with or without $1 \mu \mathrm{M}$ genistein, $1 \mathrm{mg}$ total RNA was obtained. Oligo-dT (Sigma-Aldrich; Merck KGaA) purification was performed as previously described (17). Following this, polyA + RNA was compared using a mouse GE microarray version 2.0 (Agilent Technologies, Inc.). Among the mRNAs that were observed to increase by $>3$ times following treatment with genistein, 19 mRNAs with known functions (Table I) were subjected to reverse transcription-quantitative polymerase chain reaction (RT-qPCR) in order to confirm the effects of $17-\beta$-estradiol, genistein, MK-4, 17- $\beta$-estradiol + MK-4 and genistein + MK-4 at 24 and $48 \mathrm{~h}$.

Quantification of mRNAs using RT-qPCR. From $\sim 40 \mathrm{ng}$ of total RNA, first-strand cDNA was synthesized using ReverTra Ace ${ }^{\circledR}$ reverse transcriptase (Toyobo, Co., Ltd., Osaka, Japan) with 5 pmol oligo-dT primers in a $20 \mu 1$ reaction mixture, as indicated in the manufacturer's instructions, at $50^{\circ} \mathrm{C}$ for $1.5 \mathrm{~h}$. RT-qPCR was performed using the Stratagene Mx3000P qPCR System (Agilent Technologies, Inc.). The reaction mixture consisted of a final volume of $20 \mu$ containing $1 \mu 1$ of cDNA sample, 5 pmol of a set of gene-specific primers designed using Primer-3-Plus (http://primer3plus. com; Table I), and $10 \mu \mathrm{l}$ of Brilliant III Ultra-Fast SYBR Green QPCR Master Mix (Agilent Technologies, Inc.). The cycling conditions included a denaturing step at $95^{\circ} \mathrm{C}$ for $2 \mathrm{~min}$, followed by 60 cycles at $95^{\circ} \mathrm{C}$ for $5 \mathrm{sec}$ and $60^{\circ} \mathrm{C}$ for $20 \mathrm{sec}$. The number of cycles of amplification required to reach the threshold (quantification cycle; $\mathrm{Cq}$ ) were obtained using an amplification plot and the threshold line automatically reported. To determine the number of copies of the targeted mRNAs in the samples, the $\mathrm{Cq}$ values of the genes were normalized against that of $\beta$-actin using the $2^{-\Delta \Delta C q}$ method (18). RT-qPCR products were run on $1 \%$ agarose gels and were confirmed as a single band.
Immunocytochemistry of chondroadherin (CHAD), dipeptidylpeptidase 4 (DPP4/CD26) and alkaline phosphatase $(A L P)$. The protein expression levels of CHAD and DPP4 were immunocytochemically examined, with anti-ALP used as an MC3T3-E1 cell marker. The cells were seeded into BD Bio-Coat Collagen IV Cellware plates (Cosmo Bio Co., Ltd., Tokyo, Japan) at a density of $1 \times 10^{5}$ cells/well, and incubated with 17- $\beta$-estradiol, genistein, MK-4, 17- $\beta$-estradiol + MK-4 or genistein + MK-4 for 48 or 96 h. The cells were fixed with $4 \%$ (w/v) paraformaldehyde in TBS for $30 \mathrm{~min}$ at room temperature. Subsequently, the cells were washed three times with $200 \mu 1 \mathrm{TBS}$ and incubated in blocking solution containing $1 \%$ bovine serum albumin (Sigma-Aldrich; Merck KGaA) and $0.1 \%$ Tween-20 in TBS for $1 \mathrm{~h}$ at room temperature. Following a further wash with TBS, the fixed cells were incubated overnight at $37^{\circ} \mathrm{C}$ with a goat polyclonal anti-ALP antibody $(5 \mu \mathrm{g} / \mathrm{ml}$; cat. no. AF2910; R\&D Systems, Inc., Minneapolis, MN, USA), rabbit polyclonal anti-CHAD antibody (dilution, 1:500; cat. no. NBP1-87031, Novus Biologicals, LLC, Littleton, CO, USA) and a rabbit polyclonal anti-DPP4 antibody (dilution, 1:500; cat. no. sc-9153, Santa Cruz Biotechnology, Inc., Dallas, TX, USA). The cells in each well were then washed three times with TBS, and incubated with fluorescein isothiocyanate-conjugated anti-goat and tetramethylrhodamine-conjugated anti-rabbit secondary antibodies (dilution, 1:800; cat. nos. T6778 and F7367, respectively; Sigma-Aldrich; Merck KGaA) for $1 \mathrm{~h}$ at room temperature. The cells were incubated with DAPI (Cell Signaling Technology, Inc., Danvers, MA, USA) for nuclear staining and were viewed under a BZ-8000 All-in-One Fluorescence Microscope (Keyence Corporation, Osaka, Japan).

Measurement of ALP activity. The activity of ALP was measured in $1 \times 10^{5}$ MC3T3-E1 cells in 12-well culture plates after $96 \mathrm{~h}$ of treatment. The cells were fixed with $4 \%$ (w/v) paraformaldehyde in TBS for $30 \mathrm{~min}$ at room temperature and washed three times in TBS. The activity of ALP was measured by adding $0.25 \mathrm{mg} / \mathrm{ml}$ naphthol AS-BI phosphate (Sigma-Aldrich; Merck $\mathrm{KGaA}$ ) for $1 \mathrm{~h}$. Following a wash with TBS, ALP activity levels were measured via image capture using a Canon IXY 50S camera (Canon Inc., Tokyo, Japan) and intensity measurement using Adobe Photoshop version-20160113.r.355 x64 (Adobe Systems, Inc., San Jose, CA, USA).

Statistical analysis. All values are presented as the mean \pm standard deviation. In order to compare the differences between the control and treatment groups, all groups were compared using one-way analysis of variance with Tukey's honest significant difference applied as a post hoc test (19). Statistically significant differences are indicated in each table. Analyses were performed using SPSS software (version 19; IBM SPSS, Armonk, NY, USA). P<0.05 was considered to indicate a statistically significant difference.

\section{Results}

The half-maximal inhibitory concentration of genistein against $17-\beta$-estradiol is reportedly $145 \mathrm{nM}$ for estrogen receptor $\alpha$ and $8.4 \mathrm{nM}$ for estrogen receptor $\beta$, and the two receptors are almost completely occupied by genistein at concentrations of 
Table I. mRNAs with expression increased $>3$ fold in the microarray assay following $24 \mathrm{~h}$ treatment with $1 \mu \mathrm{M}$ genistein were subjected to reverse transcription-quantitative polymerase chain reaction to validate the expression level change.

\begin{tabular}{|c|c|c|c|}
\hline \multirow[b]{2}{*}{ Accession no. } & \multirow[b]{2}{*}{ Gene name (genetic symbol) } & \multicolumn{2}{|c|}{ Primer sequence } \\
\hline & & Forward & Reverse \\
\hline NM_007432 & $\begin{array}{l}\text { Alkaline phosphatase } 3 \text {, intestine, } \\
\text { not Mn requiring (ALP3) }\end{array}$ & agaagctgcaataccacaac & atttggttgctgttggaact \\
\hline NM_015804 & ATPase, class VI, type 11A (ATP11A) & gacttgtgggtgtgtcgatg & ggaagagaactgggtggaca \\
\hline NM_007541 & Bone $\gamma$ carboxyglutamate protein (BGLAP) & gggcagagagagaggacagg & acctgtgctgccctaaagc \\
\hline NM_007557 & Bone morphogenetic protein 7 (BMP7) & atggtggtatcgagggtgga & tctcctaccectacaaggcc \\
\hline NM_013878 & Calcium binding protein 2 (CABP2) & ggacccatcagctccacaaa & ccaggagtttgaccgagacc \\
\hline NM_007689 & Chondroadherin (CHAD) & tggataatgggagggaacg & aaatccccgaccaagaggt \\
\hline NM_010074 & Dipeptidylpeptidase 4 (DPP4) & gttctggggacaggcatc & ccagcacatctattcccaca \\
\hline NM_015744 & $\begin{array}{l}\text { Ectonucleotide pyrophosphatase/ } \\
\text { phosphodiesterase } 2 \text { (ENPP2) }\end{array}$ & gcaggtatgtcttgagggtca & ctcgggtgagggacatcg \\
\hline NM_010258 & GATA binding protein 6 (GATA6) & gcatttttgctgccatctg & aaccccgagaacagtgacc \\
\hline NM_008398 & Integrin $\alpha 7$ (ITGA7) & cagatcgcatggcactttcg & atcctcagcacctctgggat \\
\hline M21041 & Microtubule-associated protein 2 (MAP2) & accaggatgccagatttggg & accttcctccatcctccetc \\
\hline NM_144557 & $\begin{array}{l}\text { Myosin VIIA and Rab interacting protein } \\
\text { (MYRIP) }\end{array}$ & ttcttcaggaccttggcact & agagctgctgctcctaccag \\
\hline ВC059256 & Notch gene homolog 2 (NOTCH2) & agagagcgagggaagatgga & gagcacccatacctgacacc \\
\hline NM_172766 & $\begin{array}{l}\text { Nuclear factor related to } \kappa \mathrm{B} \text { binding } \\
\text { protein (NFRKB) }\end{array}$ & cccttggagaccetgctaag & aaagcctcetggtccettg \\
\hline NM_008873 & Plasminogen activator, urokinase (PLAU) & gtgttggectttcctcggta & gtggcagtgtacttggagct \\
\hline NM_173413 & $\begin{array}{l}\text { RAB8B, member RAS oncogene family } \\
\text { (RAB8B), mRNA }\end{array}$ & ccacaggaatgaacgacca & gagagcaacgagcatttgtttt \\
\hline NM_009446 & Tubulin, $\alpha 3$ (TUBA3) & cgtggtattgctcagcatgc & agtttgecatctacceagcc \\
\hline NM_009521 & $\begin{array}{l}\text { Wingless-related MMTV integration site 3A } \\
\text { (WNT3A) }\end{array}$ & ggtgtttctccaccaccatc & cgctcagctatgaacaagca \\
\hline NM_009524 & $\begin{array}{l}\text { Wingless-related MMTV integration site 5A } \\
\text { (WNT5A) }\end{array}$ & ccaaacagctgcaacacctc & cagaaccagccacttagggg \\
\hline NM_007431 & $\begin{array}{l}\text { Alkaline phosphatase, liver/bone/kidney } \\
\text { (ALPL) }\end{array}$ & ctacgcaccetgttctgagg & ggcgtccatgagcagaacta \\
\hline
\end{tabular}

1-10 $\mu \mathrm{M}$ (20). Thus, the effects of $0.1-100 \mu \mathrm{M}$ of genistein on MC3T3-E1 cell growth were examined (Fig. 1). This revealed that $100 \mu \mathrm{M}$ genistein inhibited cell growth at 24 and $98 \mathrm{~h}$. Thus, in order to select mRNAs that may be involved in modifying osteoblastic function, mRNAs from cells treated with and without $1 \mu \mathrm{M}$ of genistein were compared using microarray analysis at $24 \mathrm{~h}$. Among the mRNAs from genistein-treated cells, almost 13,000 spots were revealed to exhibit a $>3$ fold higher signal compared with mRNAs from cells not treated with genistein. Of these, the mRNAs without any known function were removed, and those potentially affecting osteoblastic function (Table I) were selected and subjected to RT-qPCR in order to confirm their level of expression in cultures treated with 17- $\beta$-estradiol, genistein, MK-4, 17- $\beta$-estradiol + MK-4 or genistein $+\mathrm{MK}-4$ for 24 or $48 \mathrm{~h}$.

Among the identified factors, no significant difference was observed for Wnt family member 3A (WNT3A; Table II). At $24 \mathrm{~h}$, all treated groups tended to exhibit increased GATA-binding protein 6 (GATA6) mRNA levels compared with the control; however, these differences were not significant. This effect was also observed at $48 \mathrm{~h}$, and the GATA6 level was significantly increased genistein-treated cells compared with the other treatment groups at $48 \mathrm{~h}$. At

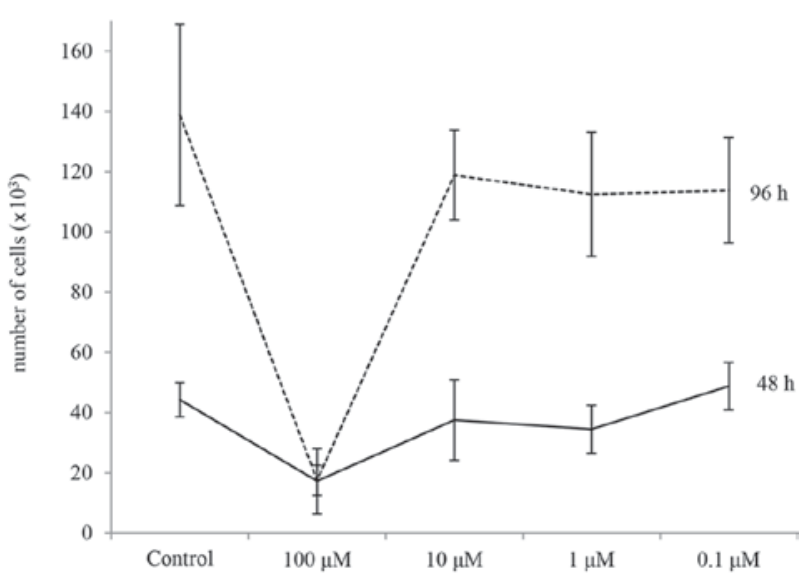

Figure 1. Proliferation of MC3T3-E1 cells with or without genistein. Values are presented as the mean \pm standard deviation.

$48 \mathrm{~h}$, the levels of NOTCH2 and WNT5A in the genistein treatment groups tended to be higher compared with those of other groups, without statistical significance. $\mathrm{NOTCH} 2$ in the MK-4 treatment group was significantly lower than that in the genistein treatment group $(\mathrm{P}=0.0475)$. 
Table II. Effects of 17- $\beta$-estradiol, genistein and/or MK-4 on mRNA levels of GATA6, NOTCH2 and WNT5A.

\begin{tabular}{|c|c|c|c|c|c|c|}
\hline \multirow[b]{2}{*}{ Treatment } & \multicolumn{2}{|c|}{ GATA6 } & \multicolumn{2}{|c|}{ NOTCH2 } & \multicolumn{2}{|c|}{ WNT5A } \\
\hline & Expression & P-value ${ }^{a}$ & Expression & P-value ${ }^{a}$ & Expression & P-value \\
\hline \multicolumn{7}{|l|}{$24 \mathrm{~h}$} \\
\hline Control & $0.01 \pm 0.01$ & 0.0018 & $0.12 \pm 0.14$ & 0.049 & $0.33 \pm 0.46$ & 0.0489 \\
\hline $17-\beta$-estradiol & $10.92 \pm 6.05$ & & $2.45 \pm 1.40$ & & $3.37 \pm 5.10$ & \\
\hline Genistein & $1.53 \pm 2.83$ & 0.0018 & $0.54 \pm 0.79$ & & $0.60 \pm 1.11$ & \\
\hline MK-4 & $3.01 \pm 3.08$ & 0.0066 & $0.04 \pm 0.10$ & 0.0281 & $1.44 \pm 2.15$ & \\
\hline 17- $\beta$-estradiol+MK-4 & $12.60 \pm 29.74$ & & $0.45 \pm 0.26$ & & $0.27 \pm 0.36$ & 0.0469 \\
\hline Genistein+MK-4 & $11.26 \pm 8.15$ & & $0.67 \pm 0.84$ & & $3.06 \pm 5.49$ & \\
\hline \multicolumn{7}{|l|}{$48 \mathrm{~h}$} \\
\hline Control & $0.75 \pm 0.73$ & 0.0012 & $1.64 \pm 1.32$ & & $2.56 \pm 2.38$ & \\
\hline $17-\beta$-estradiol & $5.36 \pm 6.67$ & 0.0097 & $3.09 \pm 4.66$ & & $6.94 \pm 9.09$ & \\
\hline Genistein & $34.20 \pm 27.60$ & & $5.58 \pm 6.61$ & & $13.16 \pm 17.21$ & \\
\hline MK-4 & $4.18 \pm 3.35$ & 0.0058 & $0.33 \pm 0.38$ & 0.0475 & $3.58 \pm 3.29$ & \\
\hline $17-\beta$-estradiol+MK-4 & $3.11 \pm 2.38$ & 0.0037 & $2.01 \pm 1.24$ & & $3.71 \pm 3.15$ & \\
\hline Genistein+MK-4 & $2.14 \pm 1.82$ & 0.0024 & $3.06 \pm 3.30$ & & $5.68 \pm 4.38$ & \\
\hline
\end{tabular}

Values are presented as the mean \pm standard deviation of 5-6 samples and expressed as $10^{-3} \mathrm{x} \beta$-actin expression. ${ }^{\mathrm{a} P}$-value vs. genistein $48 \mathrm{~h}$ group (one-way analysis of variance with Tukey's honest significant difference test as a post hoc test). No significant difference in the expression of WNT3A was confirmed among any of the groups. GATA6, GATA binding protein 6; NOTCH2, Notch gene homolog 2; WNT5A, Wnt family member 5A; MK-4, menaquinone-4.

The levels of bone $\gamma$-carboxyglutamate (BGLAP) mRNA in all treatment groups, with the exception of genistein at $24 \mathrm{~h}$, were increased compared with the control group, whether significant or not; the increase following genistein treatment at $48 \mathrm{~h}$ was statistically significant (Table III). 17- $\beta$-estradiol appeared to increase bone morphogenetic protein 7 (BMP7) mRNA at $48 \mathrm{~h}$, although this difference was not significant compared with the $48 \mathrm{~h}$ control group. The levels of CHAD and DPP4 in all of the treatment groups at $48 \mathrm{~h}$ were higher compared with those of the control; however, a significant difference was observed only in the genistein treatment group. Similarly, the levels of ectonucleotide pyrophosphatase/phosphodiesterase 2 (ENPP2) mRNA tended to be increased following the treatments, however a significant difference was obtained only in the genistein treatment group at $48 \mathrm{~h}$. A significant increase in ATPase phospholipid-transporting 11A (ATP11A) mRNA was observed following treatment with genistein + MK-4 for $48 \mathrm{~h}$ compared with the other groups. Differences in the expression levels of the following mRNAs were not observed between the treatment and control groups: Calcium-binding protein 2 (CABP2); nuclear factor related to $\kappa \mathrm{B}$-binding protein (NFRKB); integrin subunit $\alpha 7$ (ITGA7); microtubule-associated protein 2 (MAP2); plasminogen-activator, urokinase (PLAU); RAB8B, member RAS oncogene family; and tubulin $\alpha 3$ (TUBA3).

Alterations in CHAD and DPP4 mRNA levels were similar to each other (Table III). As these encode cell membrane-bound proteins that are suitable for quantitative analysis, the changes in their protein products were examined immunocytochemically (Fig. 2). At 48 h, an effect of 17- $\beta$-estradiol on CHAD or DPP4 was not always apparent. Genistein treatment induced the appearance of small fluorescent foci for CHAD and DPP4 along with alterations in cell morphology into oval or spindle-shape following $48 \mathrm{~h}$ treatment; such an effect was not always observed following MK-4 treatment. However, treatment with 17- $\beta$-estradiol + MK-4 induced the appearance of granular and diffuse CHAD and DPP4 staining, which were also apparent in the genistein + MK-4 group. After $96 \mathrm{~h}$, alterations in the cell shape were marked in the MK-4 treatment cultures, which exhibited high intensities of CHAD and DPP4 staining. The small foci had disappeared, and larger spots along with diffuse staining appeared. These alterations were the most marked in Genistein + MK-4-treated cells.

A significant increase in ALP activity was observed only in the $96 \mathrm{~h}$ genistein + MK-4 treatment group compared with the other groups (Table IV). ALP3 mRNA was significantly increased in the $48 \mathrm{~h}$ genistein treatment compared with all other treatment and control groups (Table III), whereas alkaline phosphatase liver/bone/kidney mRNA exhibited no differences in expression in any of the treatment groups (data not shown).

\section{Discussion}

Among the Japanese population, the daily intake of genistein is reported to be $\sim 12 \mathrm{mg}(50 \mu \mathrm{mol})$ from $80 \mathrm{~g}$ of soy products (21), and people in eastern Japan typically consume $50 \mathrm{~g}$ of Nattō each day, supplying 3-5 mg of MK-7 ( 6 $\mu \mathrm{mol})$ simultaneously (22). Pre-menopause, Nattō intake is useful to promote bone formation (11). By contrast, MK-4 is contained in daily foods like meat, eggs and dairy foods, and can be consumed daily, but its concentrations are low at $1-10 \mathrm{nmol} / 100 \mathrm{~g}$, thus, MK-4 intake is very limited (15). In the present study, in order to elucidate the utility of MK-4, mRNAs that exhibited altered levels in response to genistein treatment were identified initially in MC3T3-E1 cells using a microarray. However, microarrays are not always useful for quantitative analysis. Therefore, to validate the effect of genistein and/or 


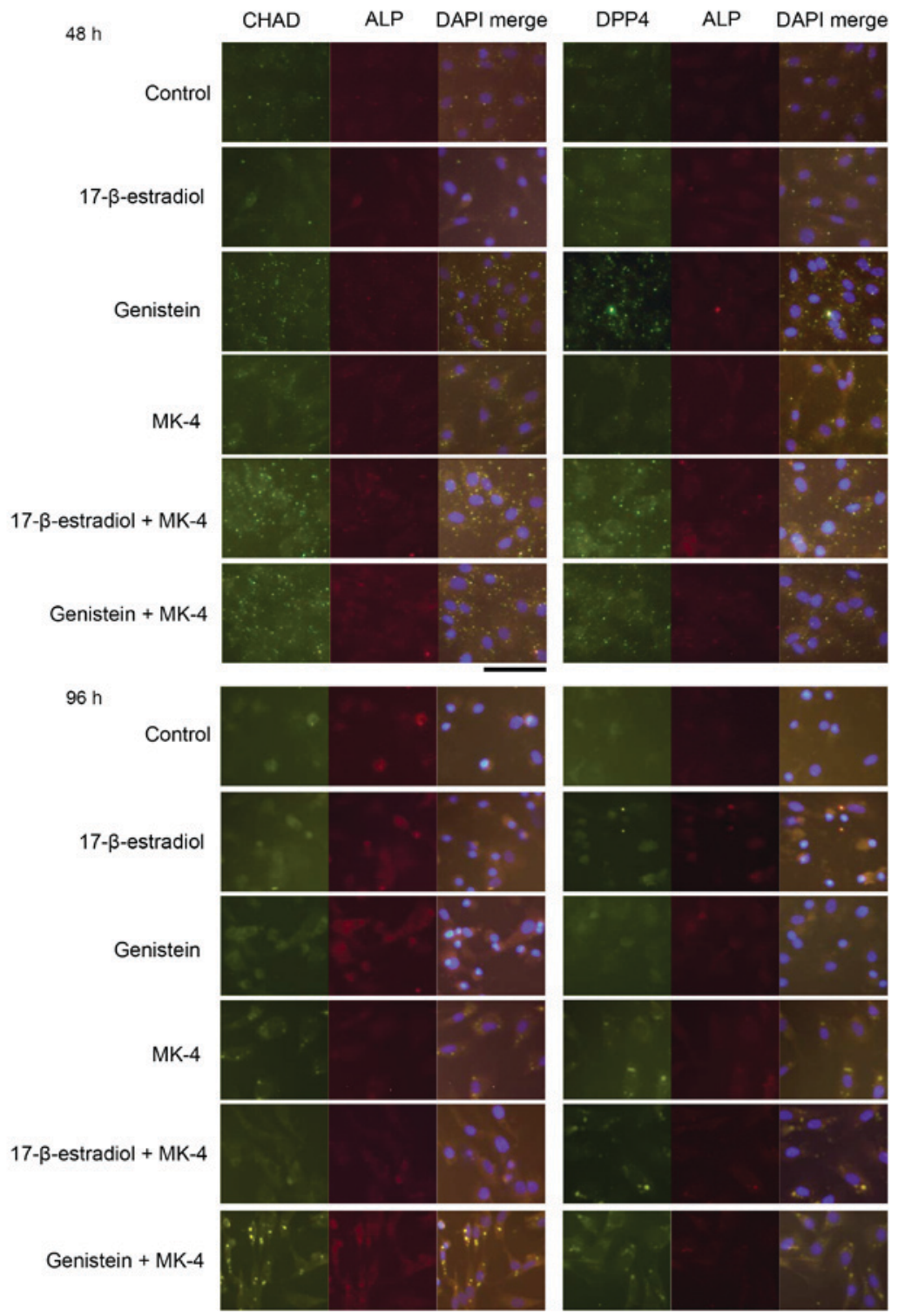

Figure 2. Immunocytochemical analysis of CHAD and DPP4 proteins in control cells and cells treated with 17- $\beta$-estradiol, genistein, MK-4, 17- $\beta$-estradiol + MK-4 or genistein + MK-4 for 48 and 96 h. Left panel, anti-CHAD or anti-DPP4 staining; center panel, anti-ALP staining; and right panel, merge with DAPI staining. Scale bar, $100 \mu \mathrm{m}$. MK-4, menaquinone-4; CHAD, chondroadherin; DPP4, pipeptidylpeptidase 4; ALP, alkaline phosphatase.

MK-4 on selected mRNAs, in comparison with the effects of $17-\beta$-estradiol, RT-qPCR was also performed.

Although the mRNAs were selected because genistein increased their levels by $>3$ fold compared with the control at $24 \mathrm{~h}$, this effect could not be confirmed in certain mRNAs. Genistein is a phytoestrogens that exerts similar effects to $17-\beta$-estradiol, although these effects are not always identical. For example, at $48 \mathrm{~h}$, a significant increase in GATA6 mRNA was observed following genistein treatment, but not following $17-\beta$-estradiol treatment. However, the $17-\beta$-estradiol + MK-4 and genistein + MK-4 maintained the expression level of GATA6 at a level consistent with that of the control group. As GATA6 is reported to suppress bone differentiation (23), the administration of estrogenic substances together with MK-4 appears to be beneficial for bone formation.

Osteoclastogenesis and bone resorption are inhibited by NOTCH1 and enhanced by NOTCH2 (24). In mouse embryonic stem cells, recombinant WNT5A has been reported to significantly enhance osteogenic yield, while recombinant WNT3A or other positive regulators of $\beta$-catenin decrease the expression of osteogenic markers (25). However, WNT5A is usually considered to promote osteoclast differentiation and prevent adipocyte differentiation (26). Genistein alone (27) and MK-4 alone $(28,29)$ reportedly promote bone formation; however, in the current study, their co-administration appeared to be more beneficial as it allowed the maintenance of NOTCH2 and WNT5A mRNAs at the levels observed in the control cells.

In the current study, genistein and/or MK-4 treatments were shown to increase BGLAP, also known as osteocalcin, indicating that this promoted an osteoblastic phenotype in the MC3T3-E1 cells. In fact, cell morphology was altered following $96 \mathrm{~h}$ treatments, also exhibiting a high intensity of ALP. The increase of BMP7 by $17-\beta$-estradiol also indicated beneficial 


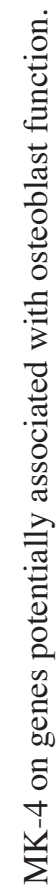

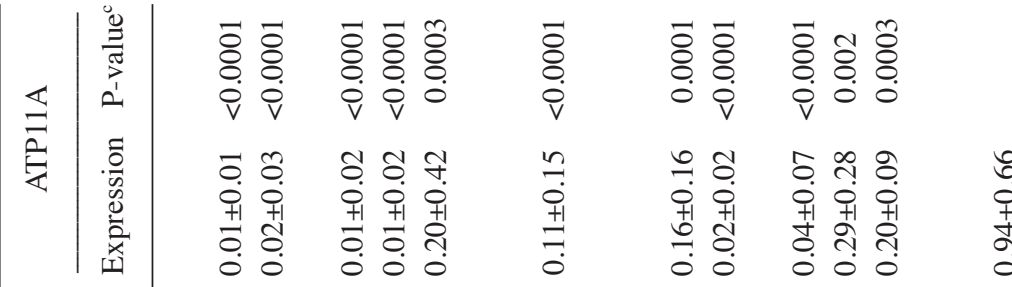

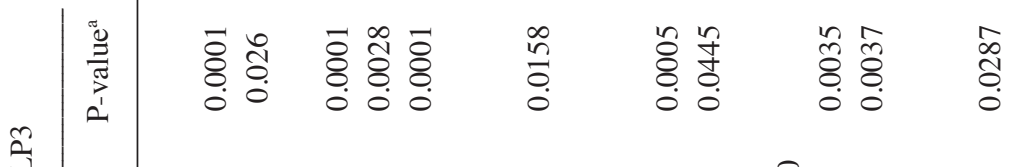

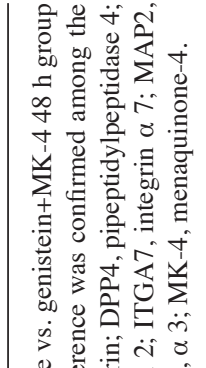

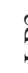

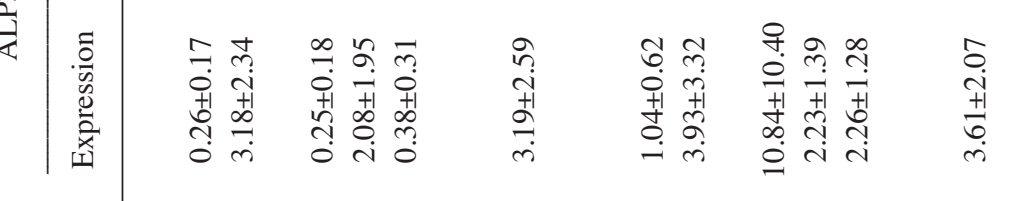

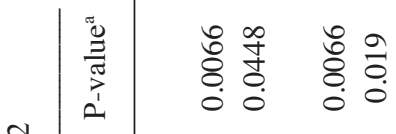

$\begin{array}{lll}\hat{m} & \overline{0} \\ \stackrel{0}{0} & \stackrel{0}{0} & 0\end{array}$

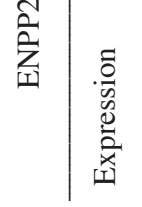

$\sin$

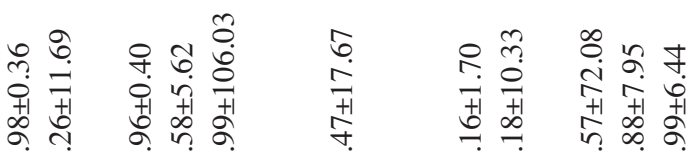

I.

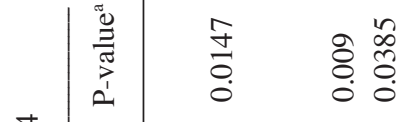

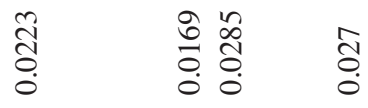

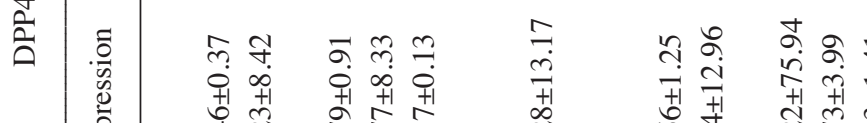

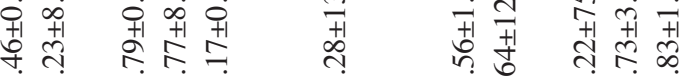

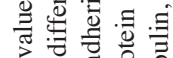

元诺

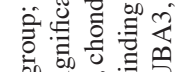

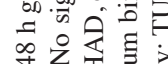

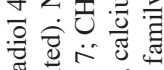

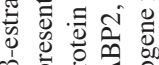

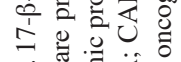

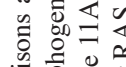

势

$\therefore$ 웡

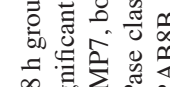

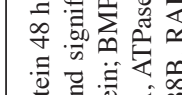

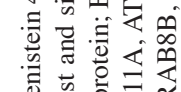

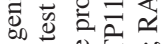

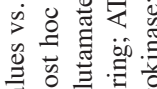

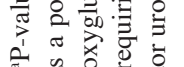

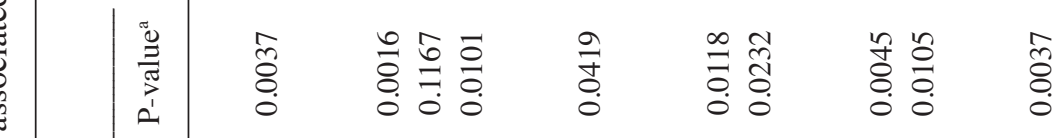

\% :

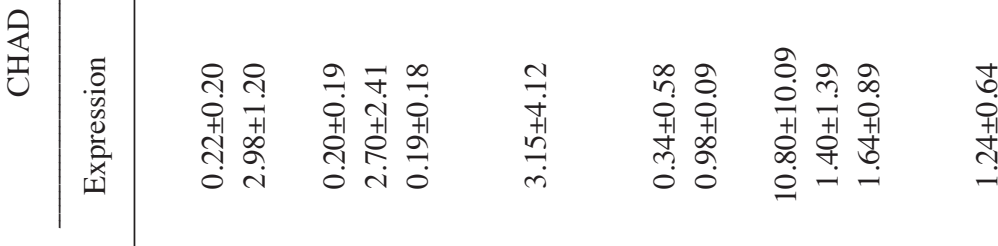

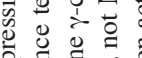

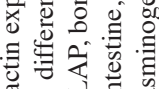

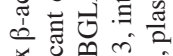

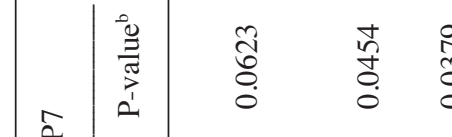

$\bar{\Xi}$

$\sum_{0}^{\infty}$

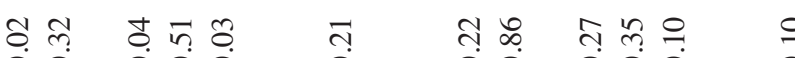

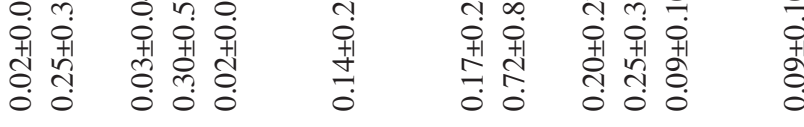

ठิ

$\begin{array}{lll}\infty & \infty & \infty \\ 0 & 0 & 0 \\ 0 & 0 & 0 \\ 0 & 0 & 0\end{array}$

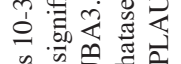

路

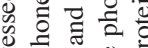

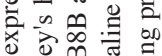

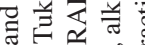

के

要过它

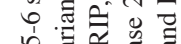

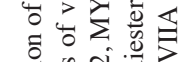

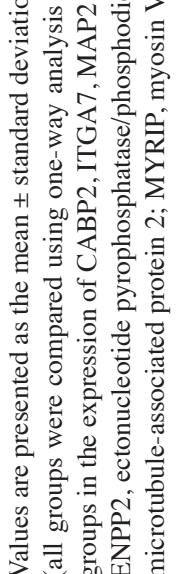


Table IV. ALP activities at $96 \mathrm{~h}$.

\begin{tabular}{lll}
\hline Treatment & ALP activity & P-value $^{\text {a }}$ \\
\hline Control & $44367 \pm 6992$ & 0.0029 \\
$17 \beta$-estradiol & $48205 \pm 8507$ & 0.0175 \\
Genistein & $42629 \pm 1646$ & 0.0013 \\
MK-4 & $41318 \pm 1379$ & 0.0007 \\
$17 \beta$-estradiol+MK-4 & $43170 \pm 2215$ & 0.0017 \\
Genistein+MK-4 & $62844 \pm 4095$ & \\
\hline
\end{tabular}

ALP activities were determined by photo and their intensity was measures by Photoshop. Thus, values are presented as the mean \pm standard deviation of 5-6 samples and expressed by an arbitrary unit from Photoshop. ${ }^{\text {a }}$-value vs. genistein + MK-4 group (one-way analysis of variance with Tukey's hones significant difference test as a post hoc test). ALP, alkaline phosphatase; MK-4, menaquinone-4.

effect of estrogenic stimulation on osteoblastic activity. The background of high activity of ALP by genistein + MK-4 was not always obvious.

Significant increases in the mRNA level of CHAD by MK-4 treatment were not consistently observed within $48 \mathrm{~h}$, whereas strong expression of its protein was clearly visible by immunocytochemistry. CHAD has been reported to reduce preosteoclast motility and bone resorption without affecting osteoblast parameters, including the expression of runt related transcription factor 2 and BGLAP, the activity of ALP and bone formation (30). Therefore, the findings of the current study indicated a beneficial effect on bone formation in response to genistein $+\mathrm{MK}-4$ treatment. However, the expression of DPP4 does not always appear to be beneficial for bone formation (31). Type 2 diabetes is associated with an increased risk of fracture. Incretins (gastric inhibitory polypeptide, glucagon like peptide 1, and 2) have an important role in the regulation of bone turnover and insulin release, and are digested by DPP4 (31). Therefore, DPP4 inhibitors appear to be useful for patients with type 2 diabetes, to ameliorate diabetes and also to prevent bone fracture. DPP4 is potentially induced by genistein and/or MK-4, of which intake is inevitable in healthy people via daily food consumption; however the concentrations obtained from food tend to be low.

ENPP2 encodes a secreted protein (32), which is therefore unsuitable for immunocytochemical analysis and was not assessed in the current study. Acidosis increases the mRNA levels of ENPPs and potentially contributes to decreased mineralization. However, among these ENPP proteins, the level of ENPP2 is not high in osteoblasts (33). ATP11A likely drives the transport of ions, such as calcium, across membranes (34); therefore, its increase by genistein + MK-4 treatment may be beneficial for the maintenance of bone.

In summary, the results of the present study suggest that the administration of genistein and/or MK-4 may be beneficial to maintain and/or improve BMD and bone metabolism. Compared with MK-7, the dietary intake of MK-4 is more common, despite its low concentration in foods. The simultaneous administration of MK-4 and genistein appears to have a substantial beneficial effect; thus, the consumption of beans with meat, eggs and dairy foods is advisable to increase osteoblastic activity.

\section{Acknowledgements}

This work was in part supported by the Grant-in-Aid, Ministry of Education, Culture, Sports, Science and Technology, Japan (grant no. C-165904748124).

\section{References}

1. Milgram JW: Adult bone structure. In: Radiologic and Histrogic Pathology of Nontumorous Diseases of Bone and Joints. Vol 1. Northbrook Publishing Co. Inc. Illinoi, USA, pp1-5, 1990.

2. Czernick B: Morphology of normal bone. In: Dolfman and Czernick's Bone Tumors. 2nd edition. Elsevier, Philadelphia, USA, pp3-12, 1998.

3. Matsuo K and Irie N: Osteoclast-osteoblast communication. Arch Biochem Biophys 473: 201-209, 2008.

4. Turner RT, Riggs BL and Spelsberg TC: Skeletal effects of estrogen. Endocr Rev 15: 275-300, 1994.

5. Ballane G, Cauley JA, Luckey MM and Fuleihan Gel-H: Secular trends in hip fractures worldwide: Opposing trends East versus West. J Bone Miner Res 29: 1745-1755, 2014.

6. Zaheer K and Humayoun Akhtar MH: An updated review of dietary isoflavones: Nutrition, processing, bioavailability and impacts on human health. Crit Rev Food Sci Nutr 57: 1280-1293, 2017.

7. Hertrampf T, Gruca MJ, Seibel J, Laudenbach U, Fritzemeier KH and Diel P: The bone-protective effect of the phytoestrogen genistein is mediated via ER alpha-dependent mechanisms and strongly enhanced by physical activity. Bone 40: 1529-1535, 2007.

8. Hur HG, Lay JO Jr, Beger RD, Freeman JP and Rafii F: Isolation of human intestinal bacteria metabolizing the natural isoflavone glycosides daidzin and genistin. Arch Microbiol 174: 422-428, 2000.

9. Katsuyama H, Arii M, Hinenoya H, Matsushima M, Fushimi S, Tomita M, Okuyama T, Hidaka K, Watanabe Y, Tamechika Y and Saijoh K: Alterations in bone turnover by isoflavone aglycone supplementation in relation to estrogen receptor $\alpha$ polymorphism. Mol Med Rep 3: 531-535, 2010.

10. Kaneki M, Hodges SJ, Hosoi T, Fujiwara S, Lyons A, Crean SJ, Ishida N, Nakagawa M, Takechi M, Sano Y, et al: Japanese fermented soybean food as the major determinant of the large geographic difference in circulating levels of Vitamin K2: Possible implications for hip-fracture risk. Nutrition 17: 315-321, 2001.

11. Katsuyama H, Ideguchi S, Fukunaga M, Fukunaga T, Saijoh K and Sunami S: Promotion of bone formation by fermented soybean (Natto) intake in premenopausal women. J Nutr Sci Vitaminol (Tokyo) 50: 114-120, 2004.

12. Tsangalis D, Wilcox G, Shah NP and Stojanovska L: Bioavailability of isoflavone phytoestrogens in postmenopausal women consuming soya milk fermented with probiotic bifidobacteria. Br J Nutr 93: 867-877, 2005.

13. Schurgers LJ and Vermeer C: Determination of phylloquinone and menaquinones in food. Effect of food matrix on circulating vitamin K concentrations. Haemostasis 30: 298-307, 2000.

14. Tsukamoto $\mathrm{Y}$, Ichise $\mathrm{H}, \mathrm{Kakuda} \mathrm{H}$ and Yamaguchi $\mathrm{M}$ : Intake of fermented soybean (natto) increases circulating vitamin K2 (menaquinone-7) and gamma-carboxylated osteocalcin concentration in normal individuals. J Bone Miner Metab 18: 216-222, 2000.

15. Elder SJ, Haytowitz DB, Howe J, Peterson JW and Booth SL: Vitamin K contents of meat, dairy, and fast food in the U.S. Diet. J Agric Food Chem 54: 463-467, 2006.

16. Sato T, Schurgers LJ and Uenishi K: Comparison of menaquinone-4 and menaquinone-7 bioavailability in healthy women. Nutr J 11: 93, 2012.

17. Davis L, Kuehl M and Battey J: Selection of Poly- $\mathrm{A}^{+}$RNA on Oligo-dT Cellulose. In: Basic Methods in Molecular Biology. 2nd edition. Appleton \& Lange, Connecticut, USA, pp344-349, 1994.

18. Livak KJ and Schmittgen TD: Analysis of relative gene expression data using real-time quantitative PCR and the 2(-Delta Delta C(T)) method. Methods 25: 402-408, 2001. 
19. Dawson-Saunders B and Trapp RG: Comparing three or more means. IN basic and clinical biostatistics. Appleton \& Lange, Connecticut, USA, pp124-141. 1990.

20. Kuiper GG, Lemmen JG, Carlsson B, Corton JC, Safe SH, van der Saag PT, van der Burg B and Gustafsson JK: Interaction of estrogenic chemicals and phytoestrogens with estrogen receptor $\beta$. Endocrinology 139: 4252-4263, 1998.

21. Takahashi T, Saito A, Hashimoto S and Sato C: Isoflavone contents of soybean and soy-based foods produced in Hokkaido. Rep Hokkaido Inst Pub Hlth 52: 29-36, 2002.

22. Standard tables of food composition in Japan. 7th edition. Ministry of Education Culture, Sports, Science and Technology, Japan 2016 (In Japanese).

23. Bhushan R, Grünhagen J, Becker J, Robinson PN, Ott CE and Knaus P: miR-181a promotes osteoblastic differentiation through repression of TGF- $\beta$ signaling molecules. Int J Biochem Cell Biol 45: 696-705, 2013.

24. Zanotti S and Canalis E: Notch signaling and the skeleton. Endocr Rev 37: 223-253, 2016

25. Keller KC, Ding H, Tieu R, Sparks NR, Ehnes DD and Zur Nieden NI: Wnt5a supports osteogenic lineage decisions in embryonic stem cells. Stem Cells Dev 25: 1020-1032, 2016.

26. Kobayashi Y, Uehara S, Udagawa N and Takahashi N: Regulation of bone metabolism by Wnt signals. J Biochem 159: 387-392, 2016.

27. Yamaguchi M: Nutritional factors and bone homeostasis: Synergistic effect with zinc and genistein in osteogenesis. Mol Cell Biochem 366: 201-221, 2012.
28. Katsuyama H, Fushimi S, Yamane K, Watanabe Y, Shimoya K, Okuyama T, Katsuyama M, Saijoh K and Tomita M: Effect of vitamin $\mathrm{K} 2$ on the development of stress-induced osteopenia in a growing senescence-accelerated mouse prone 6 strain. Exp Ther Med 10: 843-850, 2015.

29. Shikano K, Kaneko K, Kawazoe M, Kaburaki M, Hasunuma T and Kawai S: Efficacy of vitamin K2 for glucocorticoid-induced osteoporosis in patients with systemic autoimmune diseases. Intern Med 55: 1997-2003, 2016.

30. Capulli M, Olstad OK, Onnerfjord P, Tillgren V, Muraca M, Gautvik KM, Heinegård D, Rucci N and Teti A: The C-terminal domain of chondroadherin: A new regulator of osteoclast motility counteracting bone loss. J Bone Miner Res 29: 1833-1846, 2014

31. Meier C, Schwartz AV, Egger A and Lecka-Czernik B: Effects of diabetes drugs on the skeleton. Bone 82: 93-100, 2016

32. Hausmann J, Kamtekar S, Christodoulou E, Day JE, Wu T, Fulkerson Z, Albers HM, van Meeteren LA, Houben AJ, van Zeijl L, et al: Structural basis for substrate discrimination and integrin binding by autotaxin. Nat Struct Mol Biol 18: 198-204, 2011.

33. Orriss IR, Key ML, Hajjawi MO, Millán JL and Arnett TR: Acidosis is a key regulator of osteoblast ecto-nucleotidase pyrophosphatase/phosphodiesterase 1 (NPP1) expression and activity. J Cell Physiol 230: 3049-3056, 2015.

34. ATP11A ATPase phospholipid transporting 11A. Gene ID: 23250 https://www.ncbi.nlm.nih.gov/gene/23250 